\title{
A Comparative Field Monitoring of Column Shortenings in Tall Buildings Using Wireless and Wired Sensor Network Systems
}

\author{
Sungho Lee, ${ }^{1,2}$ Sangdae Kim, ${ }^{1}$ and Taehun $\mathrm{Ha}^{2}$ \\ ${ }^{1}$ School of Civil, Environmental and Architectural Engineering, Korea University, Seoul 136-713, Republic of Korea \\ ${ }^{2}$ Architectural Engineering Research Team, Daewoo E\&C, Suwon 440-210, Republic of Korea \\ Correspondence should be addressed to Sungho Lee; sungho.lee@daewooenc.com
}

Received 11 June 2015; Revised 18 September 2015; Accepted 20 September 2015

Academic Editor: Christos Riziotis

Copyright (c) 2016 Sungho Lee et al. This is an open access article distributed under the Creative Commons Attribution License, which permits unrestricted use, distribution, and reproduction in any medium, provided the original work is properly cited.

\begin{abstract}
A comparative field measurement for column shortening of tall buildings is presented in this study, with a focus on the reliability and stability of a wireless sensor network. A wireless sensor network was used for monitoring the column shortenings of a 58story building under construction. The wireless sensor network, which was composed of sensor and master nodes, employed the ultra-high-frequency band and CDMA communication methods. To evaluate the reliability and stability of the wireless sensor network system, the column shortenings were also measured using a conventional wired monitoring system. Two vibration wire gauges were installed in each of the selected 7 columns and 3 walls. Measurements for selected columns and walls were collected for 270 days after casting of the concrete. The results measured by the wireless sensor network were compared with the results of the conventional method. The strains and column shortenings measured using both methods showed good agreement for all members. It was verified that the column shortenings of tall buildings could be monitored using the wireless sensor network system with its reliability and stability.
\end{abstract}

\section{Introduction}

In concrete structures, vertical members, such as columns and shear walls, are continuously shortened even during construction due to vertical loads, material properties, geometry, and construction sequences [1]. In high-rise buildings, potential problems can arise from vertical shortening on the upper floors of the buildings, where the maximum cumulative shortening takes place. The shortened vertical structural elements inevitably transfer some forces to neighboring nonstructural elements, such as partitions, cladding, piping, and elevator rails, which are not designed to carry vertical loads. Differential shortenings between adjacent vertical members affect buildings with serviceability and safety problems. The cumulative differential shortening can cause the slabs to tilt, resulting in cracks in partitions and the deformation of widows. Additional stresses, such as shear forces and flexural moments, can occur in beams and slabs due to differential shortening of the columns. The effects of differential shortening are particularly pronounced in tall buildings with a central core and perimeter columns. Because the central core is generally less stressed than the perimeter columns and might be constructed in advance using climbing form, the amount of shortening is much less than that of the perimeter columns.

To minimize the effects due to length changes in columns during construction, the prediction and compensation of column shortening are required in high-rise building construction. Several researchers have developed analytical procedures to predict column shortening [2-6]. Based on the results of analytical methods, corrective actions, such as compensation for the length changes of a column, are prepared before construction. The predictive results are evaluated and altered by field monitoring of column shortening at the construction stage because several assumptions, such as the material properties and construction sequence, are used in the predictive procedure. Based on the results of field monitoring, the corrective actions can be changed during construction. Therefore, field monitoring of column shortening is important in addition to the predictive procedure in the construction of tall buildings. 
Various sensors, such as electronic gauges, FBG sensors, and vibration wire gauges (VWGs), are available for strain measurement of structural members in tall buildings. The VWG, which has excellent endurance and long-term stability, is widely used in the field measurement of column shortenings from among the different types of sensors. A conventional wired monitoring system with VWGs is comprised of sensors and data logger. The sensors are connected to a data logger through cables. To monitor many columns and walls, great cost and work are required to connect the cable. In some cases, cables are damaged by subsequent construction works. This damage degrades the stability of the field measurement and continuous management is required after the installation of sensors.

The wireless monitoring systems for tall buildings, which have been developed and introduced in recent studies, offer a viable alternative to conventional wired monitoring systems. Kijewski-Correa et al. reported on SmartSync, which used the building's existing Internet backbone as a system of virtual instrumentation cables for the SHM of Burj Khalifa, located in Dubai, United Arab Emirates [7]. Various sensors such as GPS, accelerometer, and meteorological module were installed and monitored. Although this system can reduce costs and problem with lengthy cables, it has a limit that structural performances cannot be monitored at early stages of construction, when a local network system of building is not installed. Su et al. monitored long-term structural performance of the Shanghai Tower, located in Shanghai, China, using wireless monitoring system [8]. More than 400 sensors with 11 different types were installed and connected to 11 substations through the cables. Substations, which were distributed along the heights of buildings, transmitted data to site-monitoring room wirelessly. The structural performances of the Ping An Finance Center were monitored by Li et al. [9]. The wireless scheme similar to that of Shanghai Tower was adopted. In Shanghai and Ping An tower, only the communication between the substations and temporary monitoring center was through wireless LAN and lengthy cables were used in data transmission between sensors and substations. In Guangzhou Television and Sightseeing Tower, the wireless sensing device was experimented by Ni et al. [10]. Data transmission between a wireless sensing device installed at the upper levels of the tower and a base station located at the ground level (a distance that exceeds $443 \mathrm{~m}$ ) was implemented. The measured data by the wireless accelerometer sensor was verified with data collected by a conventional cable-based monitoring method. However, only one sensor was experimented at different heights of the building. It is considered that a larger number of sensors are needed to be installed and tested. Choi et al. [11] monitored column shortenings of 72 story high-rise building, located in Busan, Korea, with the wireless sensor system. 20 strain sensors were installed in 2 floors and monitored by wireless measurement system. While a large number of wireless sensors were tested, the verification of reliability for wirelessly measured data was not performed. Although various wireless monitoring systems have been investigated for high-rise buildings, a few field applications have been reported for evaluating the

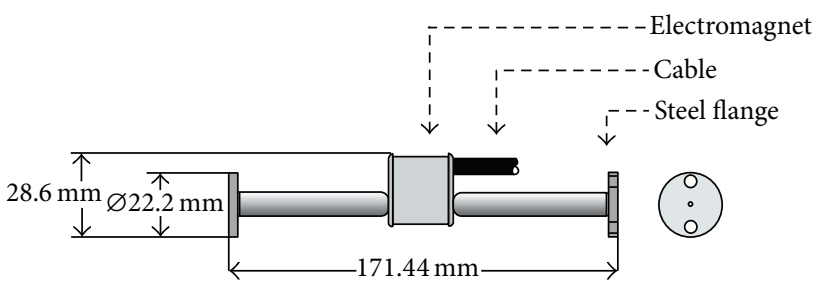

FIGURE 1: Vibration wire gauge.

reliability and stability of wireless monitoring by comparative measurements.

In this study, a wireless sensor network was applied for the monitoring column shortenings of a 58-story building under construction. To evaluate the reliability and stability of the wireless sensor network system, column shortening was also measured using the conventional wired monitoring system. Two VWGs were installed in each of the selected 7 columns and 3 walls. Based on the comparative monitoring, the reliability and stability of the wireless sensor network system are validated by comparing the measured results with those of the wired monitoring system.

\section{Wireless and Wired Sensor Network}

2.1. Sensor. The VWG is used for measuring strain in concrete structures and is suitable for direct embedding in the concrete. As shown in Figure 1, the gauge comprises a sealed tube containing a wire held in tension between two circular stainless steel flanges at both ends. An electromagnet is fitted at the center of the gauge. Strain that develops in the concrete modifies the tension in the wire and changes its resonant frequency, which is measured by the electromagnet. The strain is calculated by the measured resonant frequency of the wire according to the following equation:

$$
\varepsilon_{i}=K\left(f_{i}^{2}-f_{0}^{2}\right)
$$

where $f_{i}$ and $f_{0}$ are the initial and current natural frequencies of the wire, respectively, and $K$ is the gauge calibration factor, which includes the length, elastic modulus, mass density of wire, and gravity acceleration.

2.2. Wired Sensor Network. A conventional wired sensor network (CWSN) with VWGs is composed of sensors, a data logger, and cables that are used in connecting the sensors with the data logger. A multiplexer, which has many extended channels, can be used when the required number of sensors exceeds the available channels of the data logger. As shown in Figure 2, the data measured from the sensors are sent to the data logger through the cables and are stored in the internal memory of the data logger. The administrator can manually receive the stored data. Additionally, the data can be periodically transmitted to the server or administrator by means of a wireless LAN or Code Division Multiple Access (CDMA) technology.

Although the reliability and accuracy of a CWSN with VWGs have been validated through various experimental 


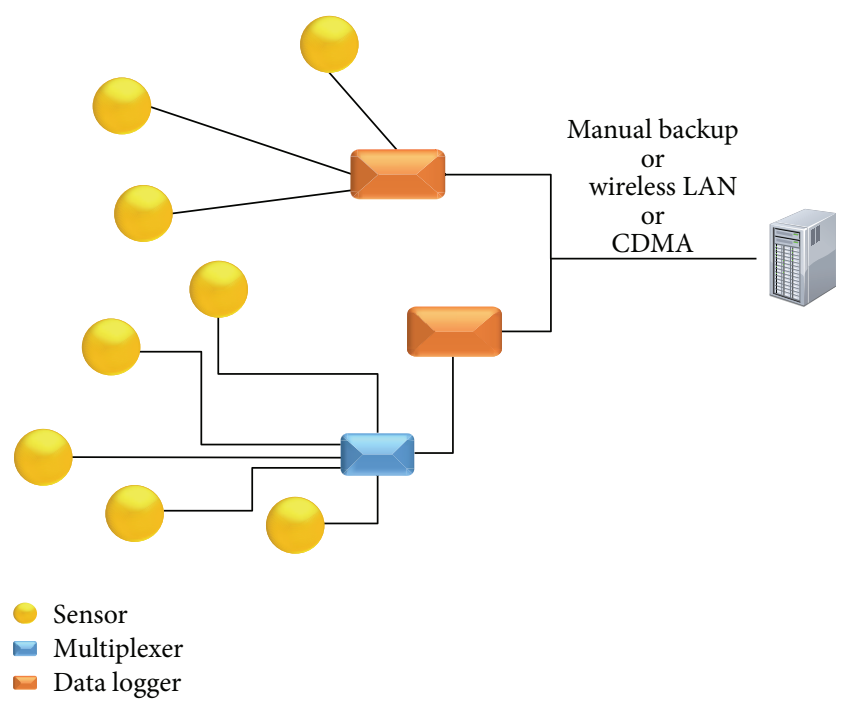

Figure 2: Conventional wired sensor network system.

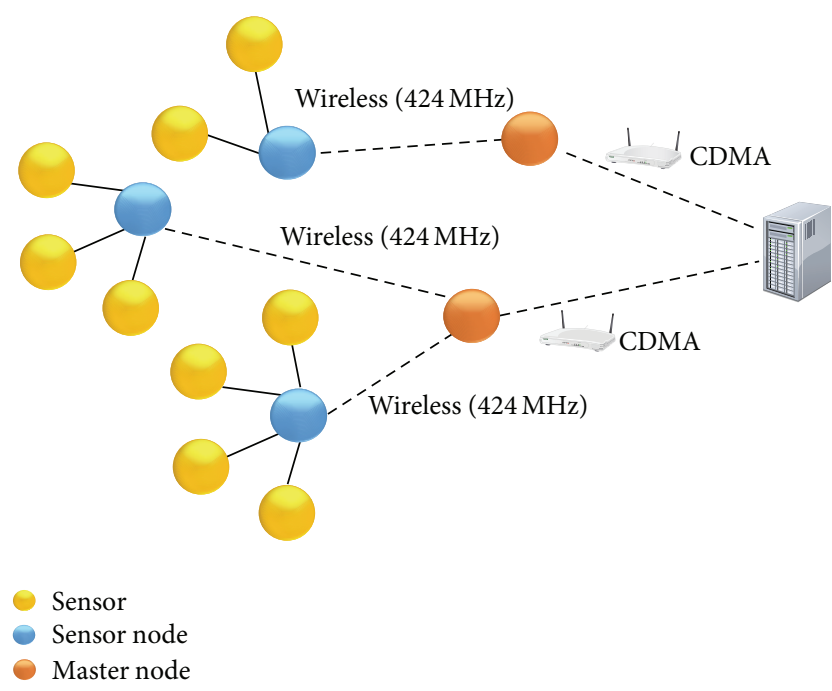

FIGURE 3: Wireless sensor network system.

tests and field applications [12-14], the costs and workloads of installing the cables and of the continuous maintenance still remain residual issues.

2.3. Wireless Sensor Network. In this study, a wireless sensor network (WSN) system based on research by Lee et al. $[15,16]$ is introduced and applied. This system is comprised of a sensor node and master node as shown in Figure 3. The sensor node, which is located in the vicinity of the sensor, receives raw data from the sensor through a short data cable. The measured strains that are processed from the raw data by a process module in the sensor node are transmitted to the master node by the wireless communication module. An ultra-high-frequency (UHF) band of $424 \mathrm{MHz}$ is used in data communications between the sensor and master node. As shown in Figure 4, four sensors can be connected to a sensor node, which has four input channels and concurrent processing capacity.

Measured strain data from the sensor node are transmitted to the server through the master node using a long-range wireless communication method. The CDMA communication module as well as the ISM module is used in the master node to transmit the measured data to the server.

\section{Comparative Field Monitoring}

3.1. Outline. To evaluate the reliability and stability of the WSN, comparative monitoring of column shortenings was performed in a residential building with a height of $189 \mathrm{~m}$, which was under construction in Chungra, South Korea. This building has 58 floors above ground and one basement level. The gross area of the building is $37,092 \mathrm{~m}^{2}$. As shown in Figure 5, the structure is symmetrical about the vertical axis with a plan of $29 \times 42 \mathrm{~m}$. The structural systems are composed of RC columns, pin walls, and core walls. Belt walls at level 30 are provided to resist lateral loads. The field monitoring of column shortening and differential shortenings between vertical members was the primary concern because the differential shortenings could affect the structural safety of the pin walls and belt walls, which have a large stiffness.

3.2. Comparative Field Monitoring. In consideration of the symmetry of the floor plan, 7 columns and 3 core walls were selected for the field monitoring. The 2nd floor, where the shortening from all of the subsequent load applications could be recorded from the beginning to the end of construction, was selected for measurement. As shown in Figure 7(a), 2 VWGs were embedded into every selected structural member and were connected with the WSN and CWSN. The locations of VWGs and the sensor network systems are shown in Figure 6.

Data cables for the CWSN were embedded into the rebar cages of the 2 nd floor slab before casting the concrete. The data logger was located inside the core walls. The data logger was configured to read the strains of selected members once every hour and to store measured strains in the internal memory, which are manually backed up to the server once a month. Wireless communications between the data logger and server, such as by means of LAN or CDMA, were excluded for accurate comparison with the WSN.

The WSN system was made up of 10 sensor nodes and 2 master nodes. As shown in Figure 8, the sensor nodes, which were connected with the VWGs through the cables, were located on the upper part of the columns and walls after casting concrete.

Two master nodes were separately installed on the column and wall in order to minimize the loss of data due to transmission interference by the wall. The locations of master nodes are shown in Figure 6(b). The sensor node was configured to measure the strains from the VWGs 12 times a day and to send these data to the master node through the wireless communication of the $424 \mathrm{MHz}$ ISM band. The WSN system was powered by an internal Li-ion battery. To minimize electric power consumption, the sleep mode 


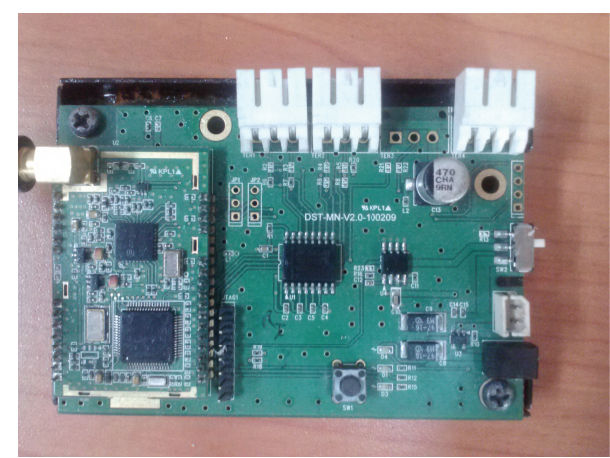

(a) Sensor node

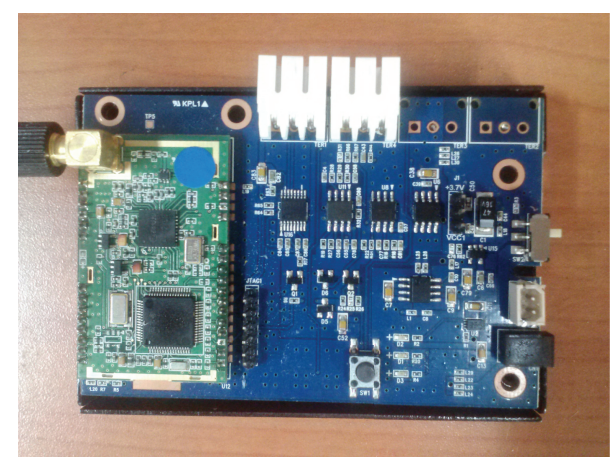

(b) Master node

FIGURE 4: Sensor node and master node.

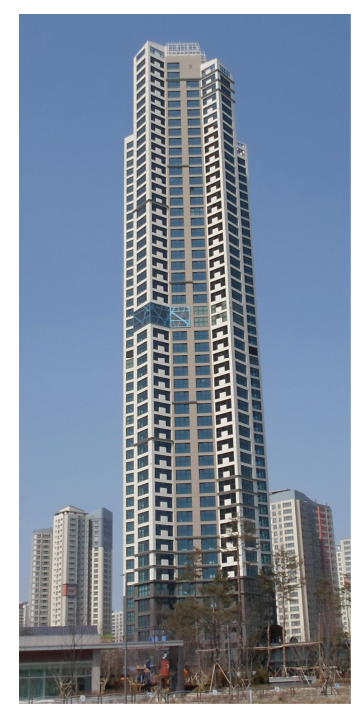

(a) Exterior

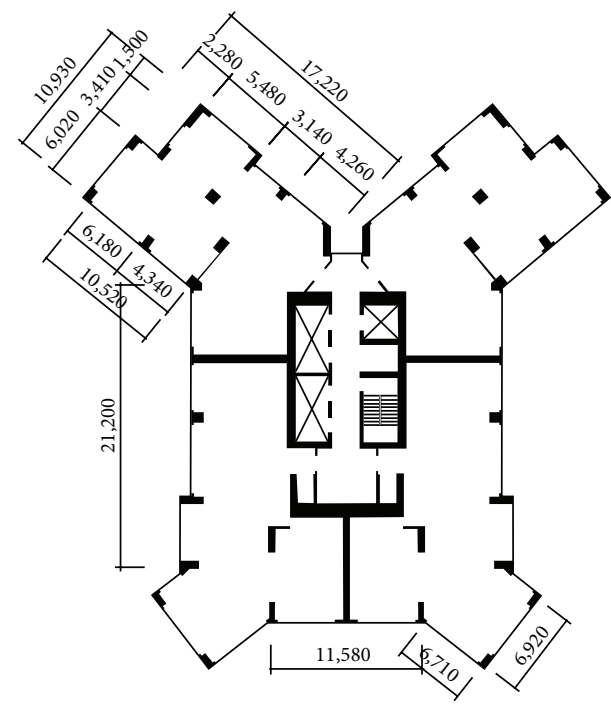

(b) Typical floor plan

FIgURE 5: Chungra residential building.

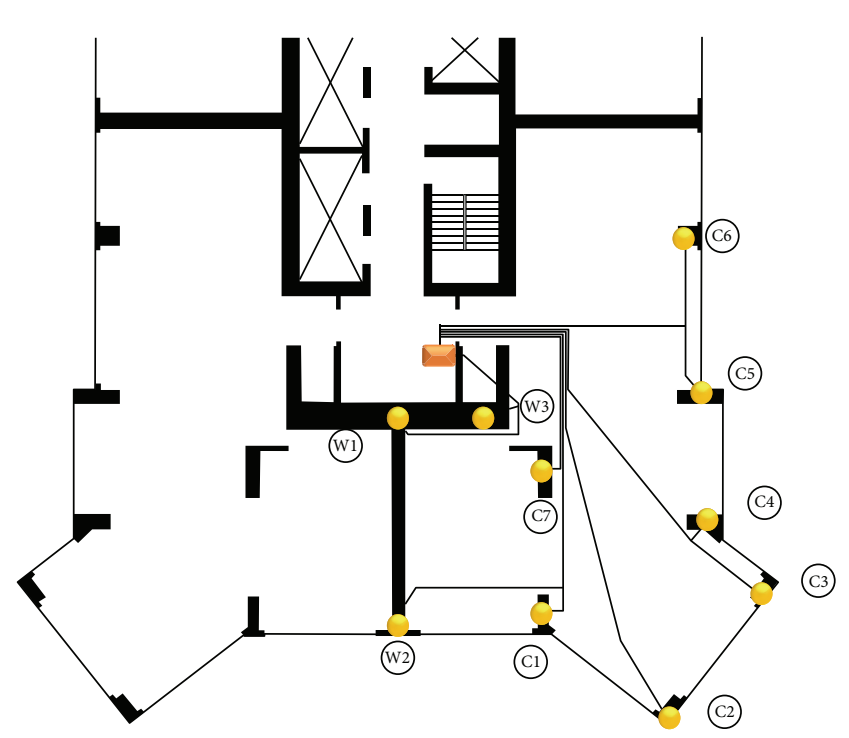

Sensor

$\square$ Data logger

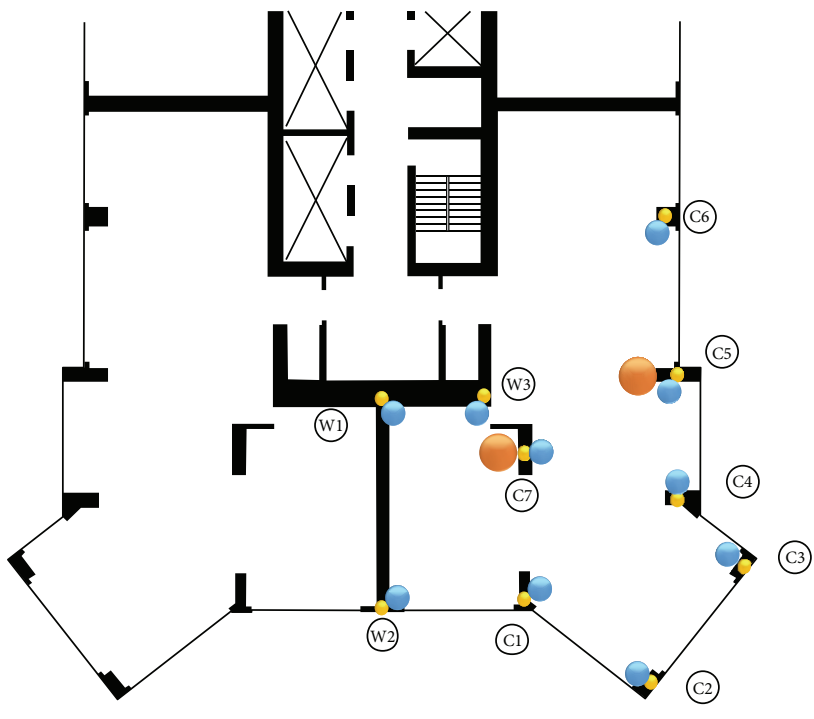

Sensor
Sensor node
Master node

(a) Layout of CWSN

(b) Layout of WSN

FIGURE 6: Configuration of the sensor network. 


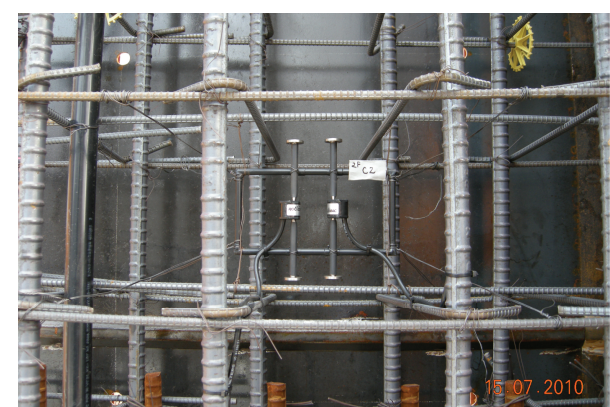

(a) Installation of VWGs

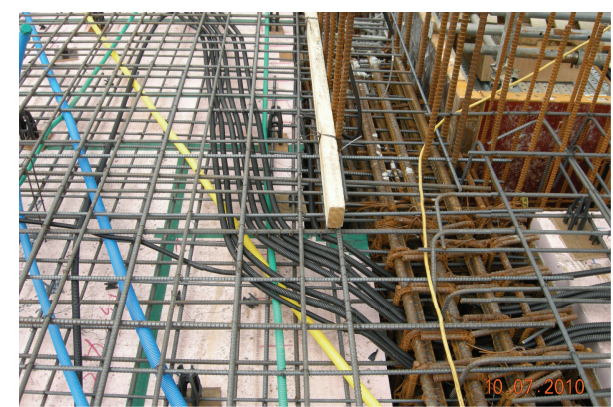

(b) Embedded cables

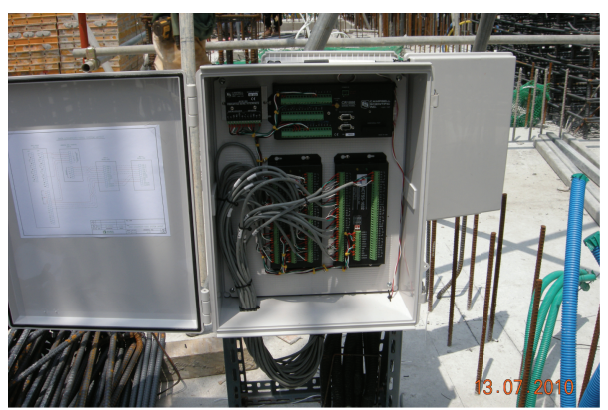

(c) Data logger

FIgURE 7: Installation of CWSN system.

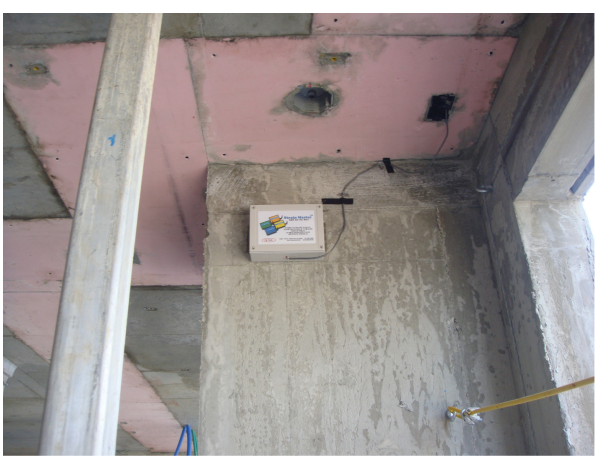

(a) Sensor node

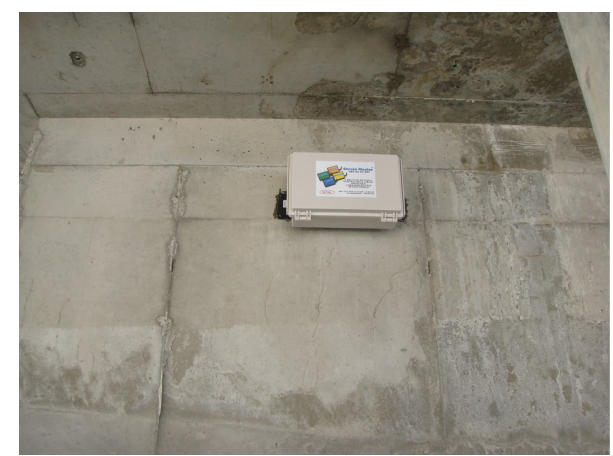

(b) Master node

FIGURE 8: Installation of WSN system.

function was used in both sensor and master nodes. After measurement at the designated times, both nodes entered into sleep mode thereby minimizing the electric power consumption of the nodes. Both nodes were configured to be awoken from sleep mode every six hours. During one hour of wake time, measurement and communication were performed every 20 minutes.

\section{Results of Field Monitoring}

4.1. Comparison of Measured Strains. Measurements for selected columns and walls on the 2 nd floor were obtained for 270 days after casting of the concrete. When internal finishes were installed in the building, measurements were ended due to interference between the finishing materials and the sensor and master nodes.

The measured strains for the C2 and C3 columns are shown in Figure 9. The compressive strains gradually increased with the subsequent construction of upper floors. Strain fluctuations due to temporary construction loads and changes in the ambient temperature were also observed using both measurement methods. The two strain curves were nearly parallel within a narrow band. Similar trends in the developing strains were observed at the WSN and CWSN.

Figure 10 shows a comparison of measured strains for wall members using the WSN and CWSN. Whereas the compressive strains of W1 gradually increased with the subsequent construction of upper floors, few strains developed at the W2 wall. These trends were similarly observed in the WSN and 


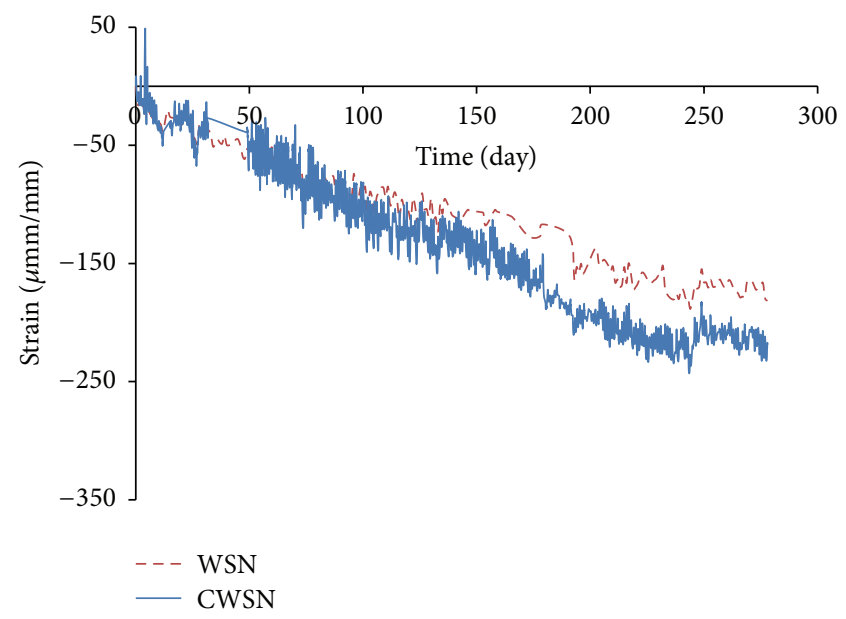

(a) C2 column

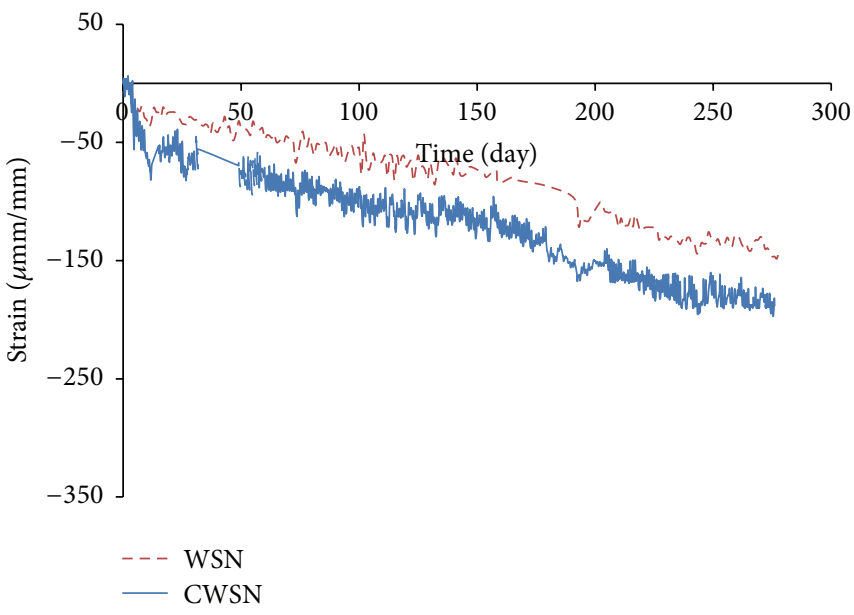

(b) C3 column

FIGURE 9: Measured strains of columns.

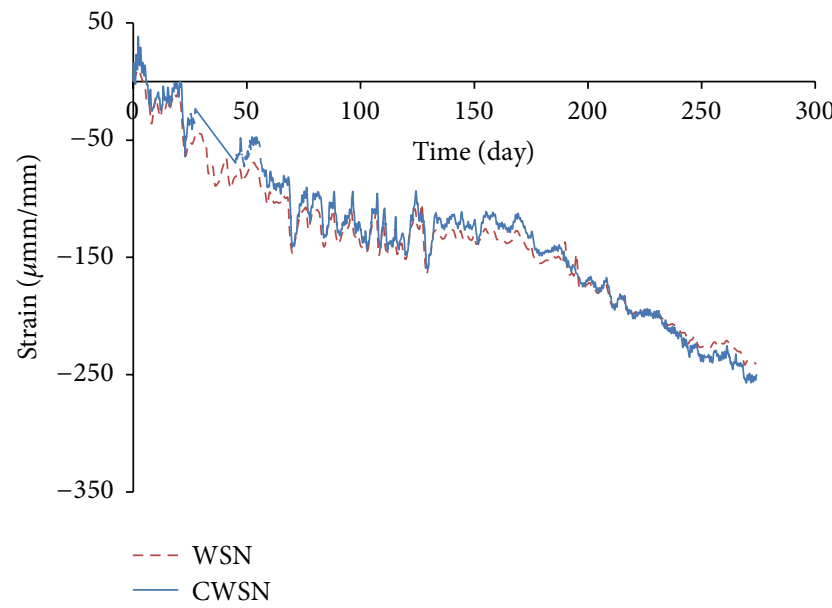

(a) W1 wall

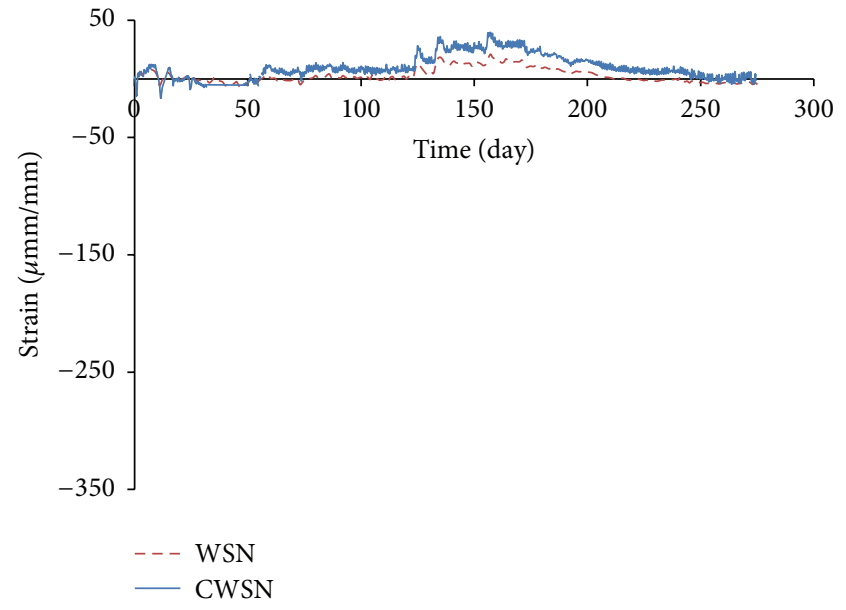

(b) W2 wall

FIGURE 10: Measured strains of walls.

CWSN. Strains measured using both measurement methods showed good agreement for the W1 and W2 walls.

The data presented in Table 1 provides basic information about the measured members and maximum strains measured by the WSN and CWSN. Maximum compressive strains from the CWSN were relatively higher than those from the WSN. Differences in the maximum strains between both methods were $10-31 \%$ for column members and 3-21\% for wall members. These differences result from the rapid strain increase in CWSN at initial measuring period. Considering that the construction sequence was not rapid, initial increasing strains measured by the CWSN were regarded as erroneous measurements due to the mechanical problems of the data logger. Except for the initial differences, the strains measured using both methods showed good agreements for all members.

Differential strains between columns are shown in Figure 11. The maximum differential strain was below 70 micro strains, which is equivalent to $0.2 \mathrm{~mm}$ differential shortening. Similar trends between the WSN and CWSN methods were obtained during the measurement period.

\subsection{Comparison of Axial Shortenings and Differential Shorten-} ing. In general, the total column shortening can be classified as shortening occurring prior to completion of construction of a certain floor (UPTO shortening) or subsequent to completion of construction of that floor (SUBTO shortening). UPTO shortening refers to shortening already developed and accumulated in the time from the start of building construction. SUBTO shortening refers to shortening developed at a certain time subsequent to when the considered floor was constructed [17]. From the measured strains by monitoring system, only the SUBTO shortening can be calculated.

Based on the strains measured by the WSN and CWSN systems, SUBTO column shortenings of each member at the 2nd floor are calculated as shown in Figure 12. Maximum column shortening value by the WSN was found to be $0.78 \mathrm{~mm}$ at $\mathrm{C} 1$. Maximum value by the CWSN also was 
TABLE 1: Basic properties and maximum strains of measured members.

\begin{tabular}{lccccc}
\hline \multirow{2}{*}{ Member } & Size $(\mathrm{cm})$ & Rebar ratio $(\%)$ & \multicolumn{2}{c}{ Maximum strain $\left(10^{-6}\right)$} & $\varepsilon_{\text {max,WSN }}$ \\
\hline C1 & $150 \times 43$ & 1.08 & -355 & -251 & $\varepsilon_{\text {max,WSN }} / \varepsilon_{\text {max }, \text { CWSN }}$ \\
C2 & $110 \times 50$ & 1.13 & -218 & -182 & 0.71 \\
C3 & $110 \times 50$ & 1.13 & -189 & -148 & 0.83 \\
C4 & $137 \times 58$ & 1.07 & -290 & -206 & 0.78 \\
C5 & $175 \times 50$ & 1.06 & -353 & -245 & 0.71 \\
C6 & $90 \times 70$ & 1.10 & -208 & -187 & 0.69 \\
C7 & $51 \times 190$ & 1.04 & -145 & -103 & 0.90 \\
W1 & $100 \times 850$ & 0.38 & -249 & -241 & 0.71 \\
W2 & $50 \times 769$ & 0.41 & -5 & -4 & 0.97 \\
W3 & $50 \times 320$ & 0.42 & -143 & -113 & 0.80 \\
\hline
\end{tabular}

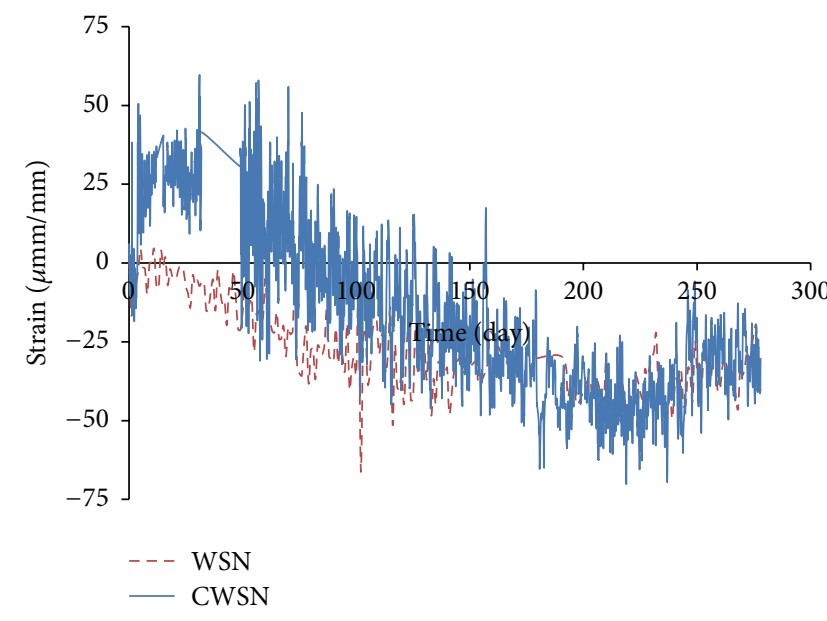

(a) Differential strains between C2 and C3

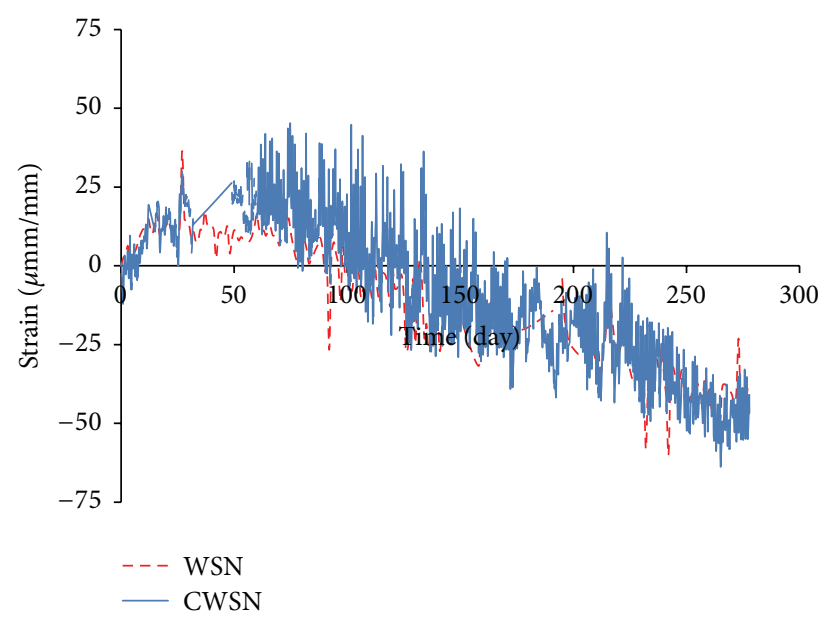

(b) Differential strains between C4 and C5

Figure 11: Measured differential strains.

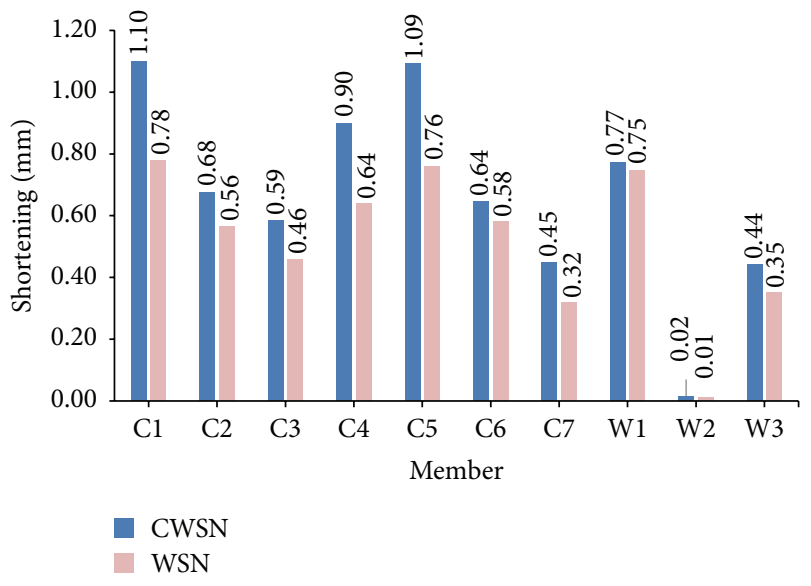

FIGURE 12: Axial shortenings measured by the WSN and CWSN.

found to be $1.10 \mathrm{~mm}$ at $\mathrm{Cl}$. The shortenings of central cores W2 and W3 were relatively smaller than those of perimeter columns. Because central core walls were generally designed to resist later loads, these core walls were less stressed than the perimeter columns against the axial loads. Differences of axial shortening between both methods were $0.07 \sim 0.33 \mathrm{~mm}$ for column members and 0.02 0.09 $\mathrm{mm}$ for wall members, respectively. Since the average of ratios of the WSN to CWSN was 0.8 , much differences between two monitoring systems were not observed. Considering that the maximum values of SUBTO shortening are greatest between two-thirds and three-quarters of the height of a tall building [17], SUBTO shortenings at lower levels tend to be small. Although the amounts of shortenings are small, the measurement shortenings at a specific floor are used for validating and correcting column shortening analysis results.

The differential shortenings between vertical members can be calculated by only SUBTO shortenings. Because every floor is usually leveled when the concrete is placed, the differences of the UPTO shortening are negligible.

Based on the SUBTO shortening values, the differential shortenings at the 2nd floor are presented in Figure 13. The differential shortenings between perimeter columns (C1 C6) were below $0.2 \mathrm{~mm}$. This meant that stress levels of perimeter columns were evenly distributed. Maximum differential shortening between the column and wall was found to be $0.77 \mathrm{~mm}$ at $\mathrm{C} 1$ column and W2 wall. Considering the clear 


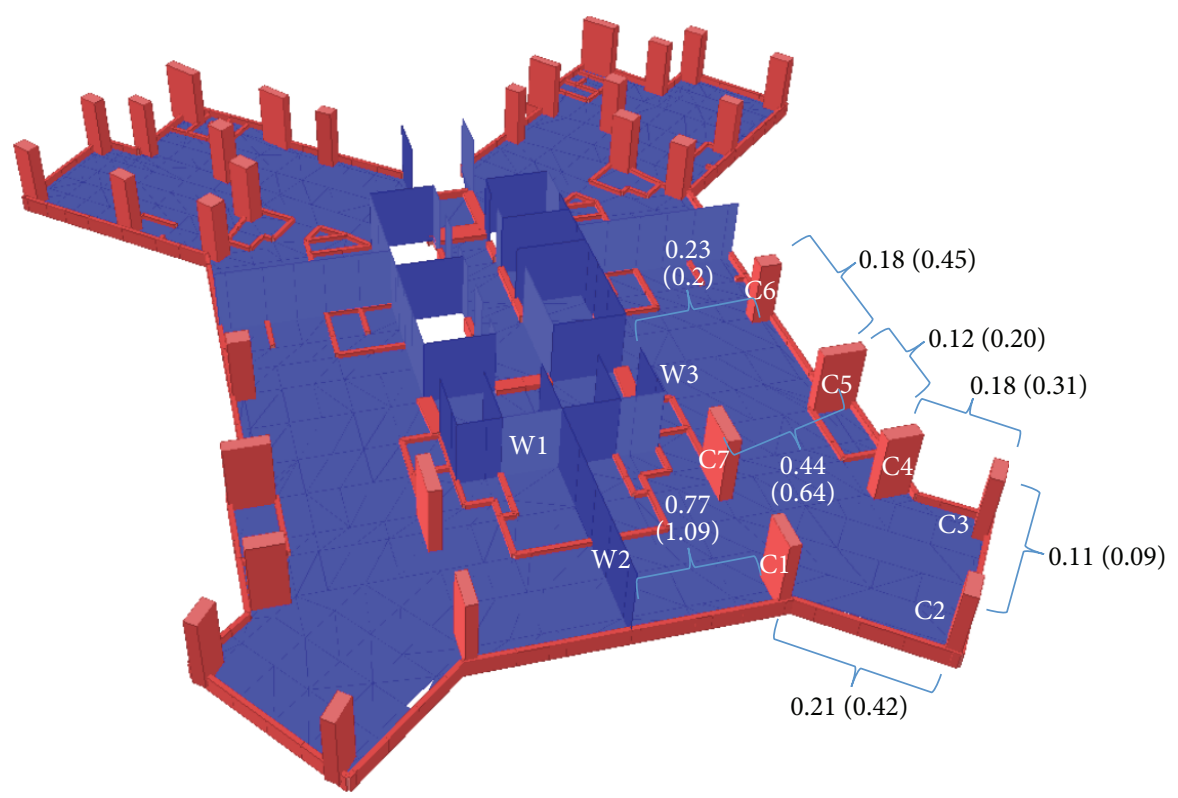

FIGURE 13: Distribution of differential shortenings of the 2nd floor measured by WSN, unit: mm (note: differential shortenings by the CWSN are presented in the parentheses).

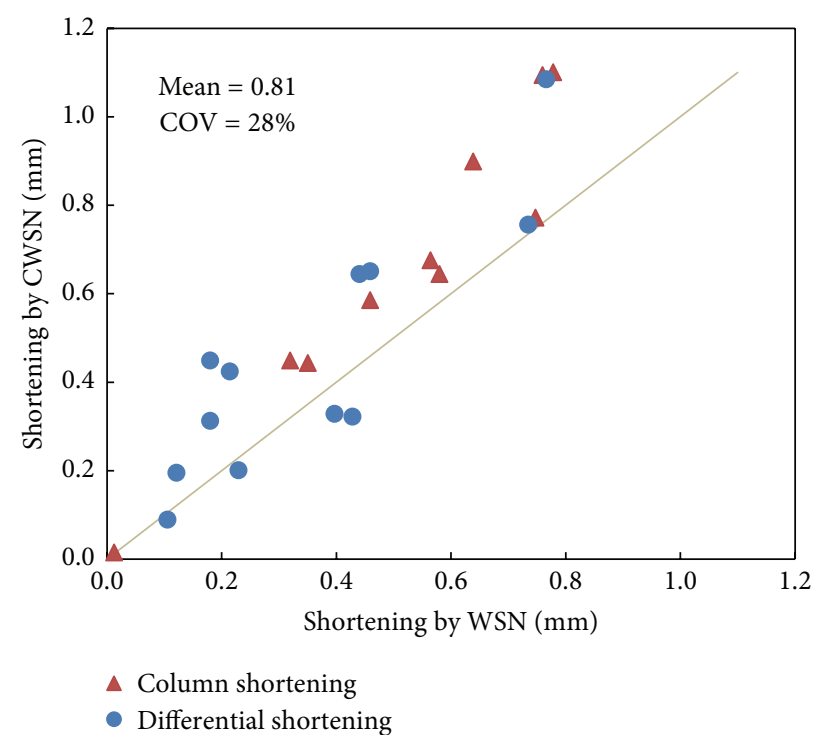

FIGURE 14: Comparison of column and differential shortenings between the WSN and CWSN.

span $(5.7 \mathrm{~m})$ between 2 members, this differential shortening will not cause the structural and serviceability problems.

The column shortenings and differential shortenings measured by the WSN were compared to those measured by the CWSN for 10 vertical members as shown in Figure 14. The shortening values by the CWSN were higher than those by the WSN. The coefficient of variation (COV) for the ratios of the WSN to CWSN is only $28 \%$ and the average value of ratios is 0.81 . Considering initial abrupt increasing in the CWSN, the shortening values measured using both methods showed good agreements for all members.

\subsection{Measurement Stability and Efficiency}

4.3.1. Comparison of Stability. To evaluate the stability of the WSN, the daily data acquisition rate was compared. The data logger of the CWSN was configured to receive measurement data hourly. The WSN was scheduled to be awoken from sleep mode every six hours. During one hour of wake time, measurement and communication were performed every 20 minutes. The daily acquisition rates of each system were estimated based on the total scheduled number of times, 24 times a day for the CWSN and 12 times a day for the WSN. As shown in Figure 15, the CWSN stably measured strains except for a portion of the measurement period. The average of the acquisition rate for the CWSN is $84 \%$, and the lowest rate is $42 \%$. No data were measured during 20 days due to a problem in the internal battery. It was considered that manual backup from the data logger caused this problem.

Data acquisition rates of the WSN for the C2 column are presented in Figure 16. For every strain reading, measurements of concrete temperature were also recorded. As the ambient temperature decreased, the WSN data acquisition rate gradually decreased. It was considered that the efficiency of the internal battery deteriorated at low temperature. The average of the WSN data acquisition rate is $54 \%$, and the lowest rate is $17 \%$. Although the average and lowest rates of the WSN are less than those of the CWSN, the WSN acquired measurement data more than 2 times a day at the least. Considering that the field measurement for column shortenings should be continuously performed throughout construction, strain readings once or twice a day are sufficient to monitor the column shortenings of tall buildings.

4.3.2. Cost and Efficiency. To compare the measurement efficiencies between two monitoring systems, cost and labor 
TABLE 2: Comparison of cost and labor for the CWSN and WSN systems.

\begin{tabular}{lcccc}
\hline \multirow{2}{*}{ Procedure } & \multicolumn{2}{c}{ CWSN } & \multicolumn{2}{c}{ WSN } \\
& Cost $^{*}$ (USD) & Labor (man-day) & Cost* (USD) & Labor (man-day) \\
\hline Installation of VWG sensors & 4,000 & 1 & 4,000 & 1 \\
Installation of cables & 4,500 & 12 & 750 & 2 \\
Installation and setting of monitoring hardware & 9,400 & 3 & 7,920 & 2 \\
Maintenance & 2,000 & 10 & 400 & 2 \\
Total & 19,900 & 26 & 13,070 & 7 \\
\hline
\end{tabular}

${ }^{*}$ Costs at each work procedure include costs of relevant materials and equipment.

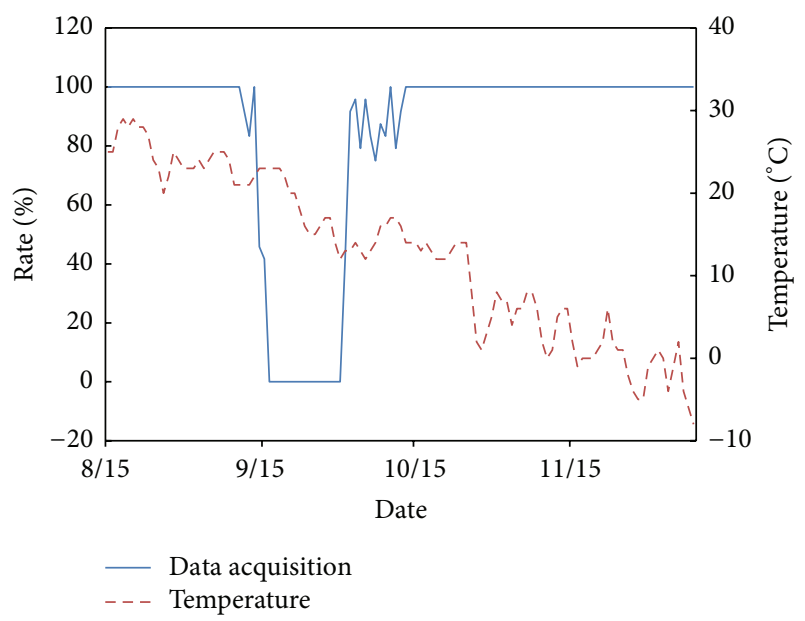

FIGURE 15: Data acquisition rates and temperatures of the C2 column using the CWSN.

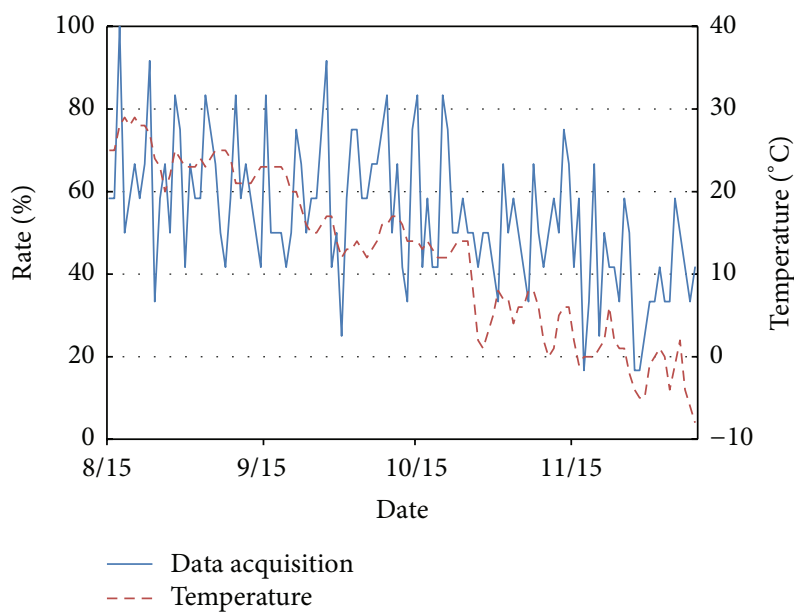

FIGURE 16: Data acquisition rates and temperatures of the C2 column using the WSN.

put into 10 vertical members were analyzed as shown in Table 2. While the total cost for the CWSN system was almost 20,000 USD, the WSN system was estimated to cost $65 \%$ of the CWSN total cost. Most of differences resulted from the costs for the procedures of cabling and its maintenance. The length of cables required for the CWNS was almost $400 \mathrm{~m}$.
With regard to labor efficiency, 7 man-days were required to install and maintain the WSN system, while 3 times more labor were needed for the CWSN system. From the comparisons, it was known that the WSN system could be costly installed and efficiently operated.

\section{Conclusions}

A comparative field measurement for column shortening in a tall building was presented in this study with a focus on the reliability and stability of a wireless sensor network. The WSN was applied for monitoring column shortenings of the 58story building under construction. To evaluate the reliability and stability of the wireless sensor network system, column shortenings were also measured using a conventional wired monitoring system. Two VWGs were installed in each of the selected 7 columns and 3 walls. Based on a comparison of the results, the following conclusions are made.

(1) Maximum compressive strains measured using the CWSN were relatively higher than those of the WSN. Although differences in the maximum strains between both methods were $10-31 \%$ for column members and $3-21 \%$ for wall members due to the initial erroneous readings from the CWSN, the two strain curves were nearly parallel within a narrow band.

(2) Although the shortening values measured by CWSN were higher than those measured by WSN, considering initial abrupt increasing in CWSN, the shortening values measured using both methods showed good agreements for all members.

(3) The average of acquisition rates for the WSN was 54\%, and the lowest rate was $17 \%$. Although the average and lowest rates of the WSN were smaller than those of the CWSN, the WSN acquired measurement data more than 2 times a day at the least. Considering that the field measurement for column shortenings should be continuously performed throughout construction, strain readings once or twice a day are sufficient to monitor column shortenings in tall buildings.

(4) The WSN system was estimated to cost $65 \%$ of CWSN's total cost. Most of differences resulted from the costs for the procedures of cabling and its maintenance. With regard to labor efficiency, 3 times more labor were needed for the CWSN system. From the comparisons, it was known that WSN system could be costly installed and efficiently operated.

(5) As compared to the CWSN system, the battery efficiency at the low temperature and the interference with the 
interior finishing works were shown to be the limits of WSN system. However, if the locations of sensor and master nodes are carefully considered, those problems will be minimized.

\section{Conflict of Interests}

The authors declare that there is no conflict of interests regarding the publication of this paper.

\section{Acknowledgment}

This research is supported by a grant from High-Tech Urban Development Program (10CHUD-A052272-01) funded by the Ministry of Land, Transport and Maritime Affairs, South Korea.

\section{References}

[1] M. Fintel, S. K. Ghosh, and H. Iyengar, Column Shortening in Tall Structure-Prediction and Compensation (EB108.01D), The Portland Cement Association, Skokie, Ill, USA, 1987.

[2] H. S. Kim, "Column shortening analysis of tall buildings considering the restraints of rebars and horizontal members," Journal of the Architectural Institute of Korea, vol. 6, no. 24, pp. 35-42, 2008.

[3] S. Maru, M. Asfaw, and A. K. Nagpal, "Consistent procedure for creep and shrinkage effects in RC frames," Journal of Structural Engineering, vol. 127, no. 7, pp. 726-732, 2001.

[4] R. K. Sharma, S. Maru, and A. K. Nagpal, "Simplified procedure for creep and shrinkage effects in reinforced concrete frames," Journal of Structural Engineering, vol. 130, no. 10, pp. 1545-1552, 2004.

[5] H.-S. Kim, S.-H. Jeong, S.-H. Shin, and J.-P. Park, "Simplified column shortening analysis of a multi-storey reinforced concrete frame," Structural Design of Tall and Special Buildings, vol. 21, no. 6, pp. 405-415, 2012.

[6] M. A. Chiorino, C. Casalegno, C. Fea, and M. Sassone, "Numerical analysis of creep and shrinkage effects in high-rise concrete or steel-concrete buildings," in Proceedings of the FIB Symposium, pp. 835-838, Prague, Czech Republic, June 2011.

[7] T. Kijewski-Correa, D. K. Kwon, A. Kareem et al., "SmartSync: an integrated real-time structural health monitoring and structural identification system for tall buildings," Journal of Structural Engineering, vol. 139, no. 10, pp. 1675-1687, 2013.

[8] J.-Z. Su, Y. Xia, L. Chen et al., "Long-term structural performance monitoring system for the Shanghai Tower," Journal of Civil Structural Health Monitoring, vol. 3, no. 1, pp. 49-61, 2013.

[9] Q. Li, Y. He, W. Hui, and K. Ju, "The structural health monitoring system," in Proceedings of the CTBUH International Conference, pp. 52-63, Shanghai, China, 2014.

[10] Y. Q. Ni, B. Li, K. H. Lam et al., "In-construction vibration monitoring of a super-tall structure using a long-range wireless sensing system," Smart Structures and Systems, vol. 7, no. 2, pp. 83-102, 2011.

[11] S. W. Choi, Y. Kim, J. M. Kim, and H. S. Park, "Field monitoring of column shortenings in a high-rise building during construction," Sensors, vol. 13, no. 11, pp. 14321-14338, 2013.

[12] H. G. Russell and S. C. Larson, "Thirteen years of deformations in water tower place," ACI Structural Journal, vol. 86, no. 2, pp. 182-191, 1989.
[13] W. F. Baker, D. S. Korista, and L. C. Novak, "Engineering the World's Tallest-Burj Dubai," in Proceedings of the CTBUH 8th World Congress, Dubai, United Arab Emirates, March 2008.

[14] W. Jiang, J. Gong, G. de Schutter, Y. Huang, and Y. Yuan, “Timedependent analysis during construction of concrete tube for tower high-rise building," Structural Concrete, vol. 13, no. 4, pp. 236-247, 2012.

[15] H. M. Lee, J. M. Kim, K. Sho, and H. S. Park, "A wireless vibrating wire sensor node for continuous structural health monitoring," Smart Materials and Structures, vol. 19, no. 5, Article ID 055004, 2010.

[16] H. S. Park, H. Y. Lee, S. W. Choi, and Y. Kim, "A practical monitoring system for the structural safety of mega-trusses using wireless vibrating wire strain gauges," Sensors, vol. 13, no. 12, pp. 17346-17361, 2013.

[17] fib Task Group 1.6, Tall Buildings: Structural Design of Concrete Buildings up to $300 \mathrm{~m}$ Tall, International Federation for Structural Concrete, 2014. 


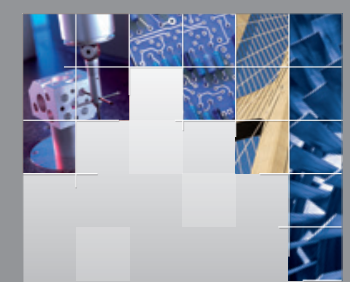

\section{Enfincering}
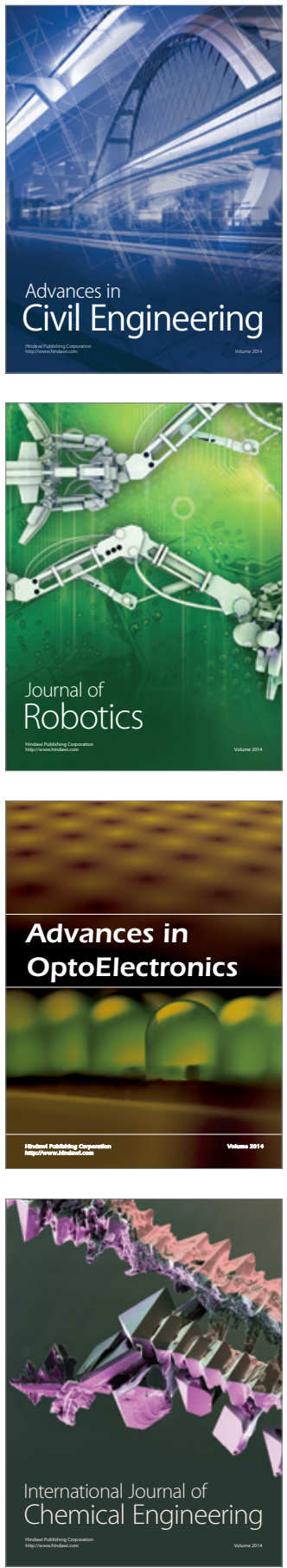

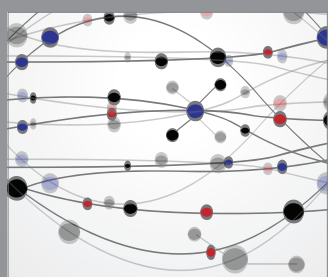

The Scientific World Journal

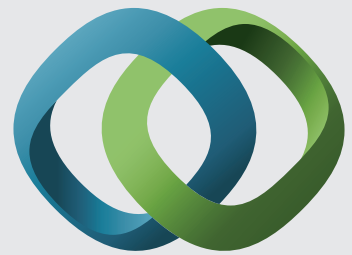

\section{Hindawi}

Submit your manuscripts at

http://www.hindawi.com
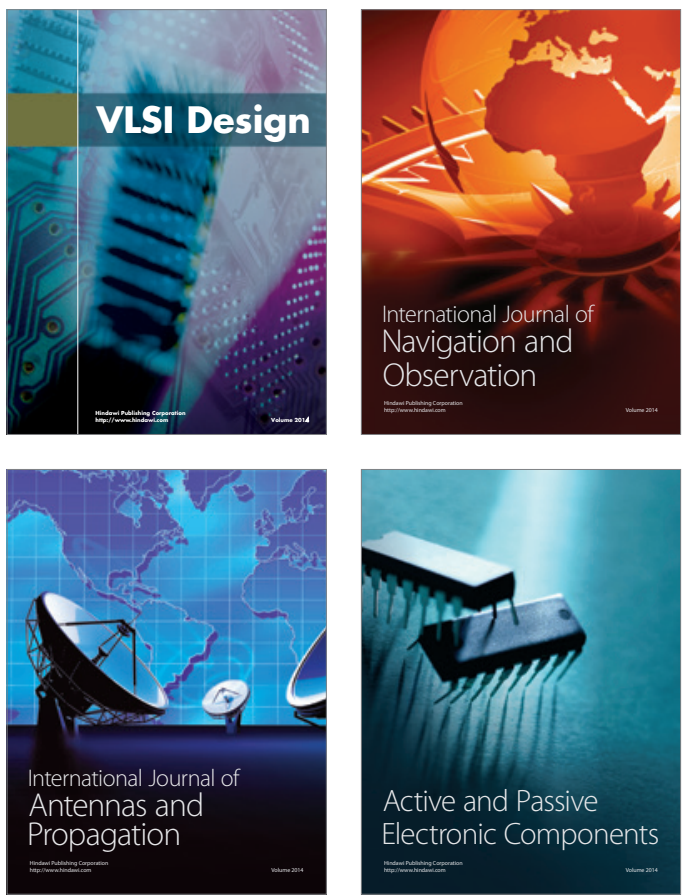
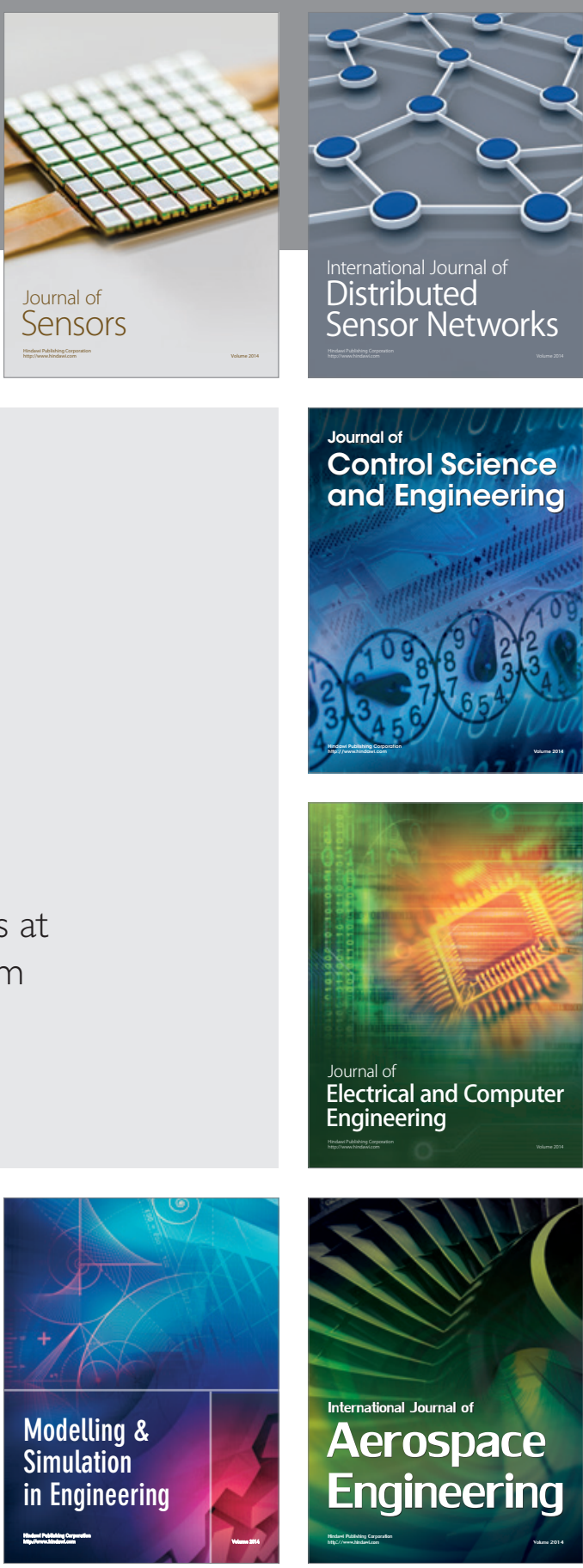

International Journal of

Distributed

Sensor Networks

Journal of

Control Science

and Engineering
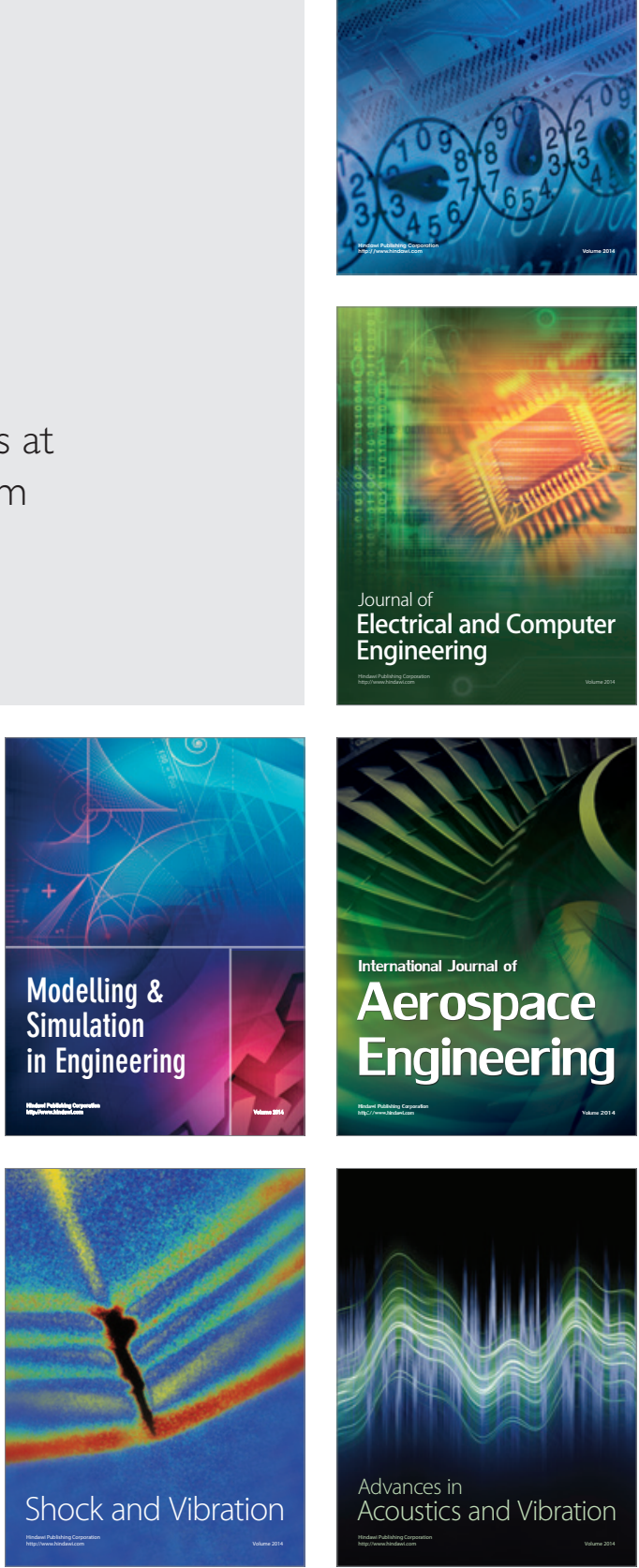